\title{
Litter live weight at birth with varying levels of D'Man germplasm
}

\author{
M. BOURFIA ${ }^{1}$ and R. W. TOUCHBERRY ${ }^{2}$ \\ 'Department of Animal Production, I.A.V. Hassan II \\ P.O.B 6202, Rabat-Instituts, Morocco \\ ${ }^{2}$ Department of Animal Science, University of California \\ Davis, CA 95616, USA
}

\begin{abstract}
A total of 208 litter birth weights, with live lambs produced in the northwest of Morocco was analyzed both by factorial analysis and by multiple regression analysis using least squares procedure. In the first model, breed group of dam and age of dam were included as fixed effects. In the second model, maternal additive and heterotic effects were included instead of breed group of dam.

Results of the first analysis indicated that breed group of dam influenced litter live weight at birth (LLWB). The crossbred S $\times$ D dams (with the sire breed listed first), and the purebred D'Man dams produced the heaviest live litters, in average 4.25 and $4.08 \mathrm{~kg}$, respectively. The purebred Beni Guil dams produced the lightest live litter, $3.32 \mathrm{~kg}$ in average. The second analysis showed that maternal additive effects were important for LLWB, and that maternal heterosis was of little importance. The ranking of maternal additive breed effects for LLWB was D'Man, Sardi, and Beni Guil in descending order.
\end{abstract}

Index words: Additive effect, heterosis, sheep crossbreeding, D'Man

\section{Introduction}

Effective use of prolific sheep in crossbreeding systems is based on exploitation of breed and heterotic effects. Little effort has been expanded in quantifying additive and heterotic effects of Moroccan breeds of sheep. The objectives of the study were to evaluate lambing performance, compare maternal additive breed differences, and assess maternal heterosis for litter live weight at birth (LLWB) with different proportions of D'Man (D) breeding.

\section{Material and methods}

D sires were mated to nine breed groups of ewes resulting from a diallel cross conducted at a station located in the northwest of Morocco (latitude $34^{\circ} 18 \mathrm{~N}$ ). The base diallel included three Moroccan breeds of sheep, i.e. D (D), Beni Guil (G), and Sardi (S). The trait stud- 
ied was LLWB, which was the sum of birth weights of lambs born in the same litter identified as live within 20 hours of birth. A total of 208 litter birth weights recorded in the winter of 1985 was analyzed by least squares procedure (3), using two models. In the first model, genetic effects were included as breed group of dam, while in the second model, genetic effects were defined in terms of maternal additive and heterotic effects. In the latter model, fractions based on the expected proportions of genes contributed by each breed for maternal additive and heterotic effects were computed as shown in table 1, and were considered as continuous variables; the genetic components were then estimated as partial regression coefficients $(2,5,6,7)$. Because of dependencies among breed additive effects, maternal additive breed effects for $\mathrm{G}$ and $\mathrm{S}$ were computed as deviations from $\mathrm{D}$. Both models included environmental effects as age of dam with two levels, i.e. 2 and 3 year old dams.

\section{Results and discussion}

LLWB represented a composite trait of prolificacy, viability, and prenatal growth, and may be regarded as an early indicator of ewe productivity. The two statistical models used in the study can be derived from the analyses of variance given in table 2 . The corresponding least squares means and regressions are provided in table 3. Age of dam was not a significant source of variation for LLWB.

Dam breed group differences. The first analysis showed that breed group of dam significantly influenced LLWB. Duncan's multiple range test as modified by KRAMER (4) revealed 3 groups of mating combinations as shown in table 3 . The crossbred $\mathrm{S} \times \mathrm{D}$ (sire breed first) and the purebred D dams demonstrated the highest LLWB with more than $4 \mathrm{~kg}$. The lowest performing group included the crossbred $\mathrm{G} \times \mathrm{D}, \mathrm{G} \times \mathrm{S}$, and $\mathrm{S} \times \mathrm{G}$, and the purebred $\mathrm{G}$ dams. Live litters out of the latter group of dams were in average more than $.5 \mathrm{~kg}$ lighter than live litters from the former group of dams.

Dam breed group components. The inferences drawn from the results can be extended after partitioning the breed group effects into its components. Among the possible reasons

Table 1. Coefficients for the fractions of maternal additive and heterotic effects that were used in model 2.

\begin{tabular}{lllllllllll}
\hline & & D & G & S & DG & GD & DS & SD & GS & SG \\
\hline Mat. Additive & D & 1 & 0 & 0 & $1 / 2$ & $1 / 2$ & $1 / 2$ & $1 / 2$ & 0 & 0 \\
& G & 0 & 1 & 0 & $1 / 2$ & $1 / 2$ & 0 & 0 & $1 / 2$ & $1 / 2$ \\
Mat. Heterosis & S & 0 & 0 & 1 & 0 & 0 & $1 / 2$ & $1 / 2$ & $1 / 2$ & $1 / 2$ \\
\hline
\end{tabular}

$\mathrm{D}=\mathrm{D}$ 'Man, $\mathrm{G}=$ Beni Guil, and $\mathrm{S}=$ Sardi. Breed of sire is listed first in the case of crossbred dams.

Table 2. Least squares analysis of variance for litter live weight at birth using two statistical models.

\begin{tabular}{|c|c|c|c|c|c|}
\hline \multicolumn{3}{|c|}{ Model 1} & \multicolumn{3}{|c|}{ Model 2} \\
\hline Source & D.F. & M.S. & Source & D.F. & M.S. \\
\hline Dam age & 1 & .005 & Dam age & 1 & .0004 \\
\hline Dam breed group & 8 & $2.252^{*}$ & $\begin{array}{l}\text { Dam breed group comp. } \\
\text { Mat. Add. G } \\
\text { Mat. Add. S } \\
\text { Mat. Heteros. }\end{array}$ & $\begin{array}{l}1 \\
1 \\
1\end{array}$ & $\begin{array}{c}13.493^{* *} \\
1.235 \\
.050\end{array}$ \\
\hline Remainder & 198 & 1.042 & Remainder & 203 & 1.033 \\
\hline
\end{tabular}

$*: \mathrm{P}<.05 \quad * *: \mathrm{P}<.01$ 
for differences in performance of dam breed groups are maternal additive and heterotic effects. Table 2 shows that maternal additive breed effects were the predominant genetic influences. Maternal additive effects for the $G$ and $\mathrm{S}$, expressed as a deviation from $\mathrm{D}$, were negative for LLWB, although only the G had significantly low performance (table 3 ). The $-.874 \mathrm{~kg} \mathrm{G}$ maternal additive influence accounts for the generally lower prolificacy of $\mathrm{G}$ ewe. Under the same management system, BourfiA (1) estimated average litter size at birth as 2.01, 1.00, and 1.11 for D, G, and $\mathrm{S}$ ewes, respectively. Maternal heterosis was not statistically significant. It should be pointed out that only average maternal heterosis was estimated, and it is possible that the magnitude of maternal heterosis in certain breed combinations might be of greater importance. Since only a relatively few dam breed groups were available, specific maternal heterosis could not be estimated because of dependency in the data.

\section{Conclusion}

The multiple regression approach provid-

\section{References}

1. BourfiA, M. 1987. Evaluation of three Moroccan breeds of sheep. PhD. Thesis. University of Minnesota. St Paul. USA.

2. Dillard, E.U., O. Rodriguez and O.W. Robison. 1980. Estimation of additive and nonadditive direct and maternal genetic effects from crossbreeding beef cattle. J. Anim. Sci. 50: 653-663.

3. Harvey, W.R. 1977. Users guide for LSML 76. Mixed model least squares and maximum likelihood computer program. Ohio State University, Columbus. USA.

4. Kramer, C.Y. 1976. Extension of multiple range test to group means with unequal numbers of replications. Biometrics, 12: 307-310.
Table 3. Least squares means, regressions, and standard errors for litter live weight at birth $(\mathrm{kg})$.

\begin{tabular}{llll}
\hline & Obs. L.S.M. & S.E. \\
\hline Dam breed group & & & \\
$\quad$ Sardi $\times$ D'Man & 15 & $4.252 \mathrm{a}$ & .276 \\
Purebred D'Man (D) & 41 & $4.081 \mathrm{a}$ & .161 \\
D'Man $\times$ Sardi & 21 & $3.886 \mathrm{ab}$ & .225 \\
D'Man $\times$ B.Guil & 19 & $3.880 \mathrm{ab}$ & .234 \\
Purebred Sardi (S) & 18 & $3.853 \mathrm{ab}$ & .245 \\
B.Guil $\times$ D'Man & 33 & $3.509 \mathrm{~b}$ & .188 \\
B.Guil $\times$ Sardi & 24 & $3.453 \mathrm{~b}$ & .210 \\
Sardi $\times$ B.Guil & 18 & $3.444 \mathrm{~b}$ & .242 \\
Purebred B.Guil (G) & 19 & $3.323 \mathrm{~b}$ & .237 \\
Dam breed group components & & & \\
Maternal additive for G (1) & & $-.874 * *$ & .242 \\
Maternal additive for S (1) & & -.261 & .239 \\
Maternal heterosis & & -.033 & .152 \\
\hline
\end{tabular}

Obs $=$ Number of observations. Breed of sire is listed first in the case of crossbred dams. Means followed by the same letter do not differ $(\mathrm{P}>.05)$.

(1) As deviation from that of the D'Man. ${ }^{* *}: \mathrm{P}<.01$.

ed a useful supplement for interpreting the differences among the various breed groups of dams. Maternal additive effects were the main causes of variation among dam breed groups for LLWB. On the basis of the magnitude of differences in maternal additive effects, it seems that use of D germplasm would increase LLWB.
5. Olson, T.A., A.V. DiJK, M. Koger, D.D. HarGrove, and D.E. Franke. 1985. Additive and heterosis effects of preweaning traits, maternal ability and reproduction from crossing of the Angus and Brown Swiss breeds in Florida. J. Anim. Sci. 61: 1121-1131.

6. Roberson, R.L., J.O. Sanders and T.C. CartWRIGHT. 1986. Direct and maternal genetic effects on preweaning characters of Brahman, Hereford and Brahman-Hereford crossbred cattle. J. Anim. Sci. 63: $438-446$.

7. Robison, O.W., B.T. McDaniel and E.J. Rincon. 1981. Estimation of direct and maternal additive and heterotic effects from crossbreeding experiments in animals. J. Anim. Sci. 52: 44-50. 